\title{
Metabolism of L-Rhamnose in Arthrobacter pyridinolis
}

\author{
By SUSAN L. LEVINSON* AND TERRY A. KRULWICH \\ Department of Biochemistry, Mount Sinai School of Medicine, \\ Iooth St and 5th Ave, New York, N.Y. I0029, U.S.A.
}

(Received 4 November 1975; revised 10 February 1976)

\begin{abstract}
S UMMAR Y
In Arthrobacter pyridinolis, a respiration-coupled transport system for Lrhamnose caused accumulation of free L-rhamnose, while a phosphoenolpyruvate: L-rhamnose phosphotransferase system caused accumulation of L-rhamnose Iphosphate (Levinson \& Krulwich, 1974). The pathways for subsequent metabolism of L-rhamnose and L-rhamnose I-phosphate have now been investigated. Arthrobacter pyridinolis contains an inducible L-rhamnose isomerase and Lrhamnulokinase, as well as a constitutive L-rhamnulose I-phosphate aldolase. Results with mutants which are unable to metabolize L-rhamnose suggest the presence of an L-rhamnose I-phosphate phosphatase, which forms free L-rhamnose by hydrolysis of L-rhamnose I-phosphate produced by the phosphotransferase system. Mutants which lack this enzyme exhibited severe inhibition of growth in the presence of L-rhamnose plus any of a variety of carbon sources. There is some evidence that this inhibition was due to accumulation of L-rhamnose Iphosphate at toxic concentrations within the bacteria. The metabolism of Lrhamnose transported by the phosphotransferase system therefore appears to occur by hydrolysis of L-rhamnose I-phosphate to free L-rhamnose by a phosphatase. Metabolism of the L-rhamnose thus produced, and of that accumulated by the respiration-coupled transport system, then proceeds by the sequence of reactions: L-rhamnose $\rightarrow$ L-rhamnulose $\rightarrow$ L-rhamnulose I-phosphate $\rightarrow$ dihydroxyacetone phosphate plus L-lactaldehyde.
\end{abstract}

\section{INTRODUCTION}

Studies of L-rhamnose metabolism in Escherichia coli (Englesberg, I957; Takagi \& Sawada, 1964a, $b$; Chiu \& Feingold, 1964, 1965, 1969) showed that L-rhamnose was metabolized via isomerization to L-rhamnulose, phosphorylation at the expense of ATP to form L-rhamnulose I-phosphate, and cleavage by an aldolase to produce dihydroxyacetone phosphate and L-lactaldehyde. The finding that there were two systems for the transport of L-rhamnose in Arthrobacter pyridinolis (Levinson \& Krulwich, 1974) raised the question of how L-rhamnose was metabolized inside this organism. One of the transport systems was a respiration-coupled system in which L-rhamnose transport was coupled to the oxidation of L-malate or succinate. Because of some unusual metabolic patterns in A. pyridinolis (Wolfson \& Krulwich, 1972), operation of this transport system depended on the presence of L-malate, or a precursor, in the medium (Levinson \& Krulwich, 1974). The respirationcoupled transport system caused accumulation of free L-rhamnose within the cell. Thus, L-rhamnose taken up by the respiration-coupled system in $A$. pyridinolis might be metabolized by the sequence of transformations known for $E$. coli. The second transport system for L-rhamnose was a phosphoenolpyruvate (PEP): L-rhamnose phosphotransferase

* Present address: Department of Physiological Chemistry, The Roche Institute of Molecular Biology, Nutley, New Jersey, U.S.A. 
system. Strains which possessed phosphotransferase activity could grow on L-rhamnose as sole carbon source, while those lacking this activity, which were dependent upon the respiration-coupled transport system, required L-malate for growth on L-rhamnose. The PEP:L-rhamnose phosphotransferase system caused uptake of L-rhamnose and accumulation of the compound as L-rhamnose I-phosphate. L-Rhamnose I-phosphate was not an intermediate in the known pathways for L-rhamnose metabolism, suggesting that an alternative pathway must exist for the metabolism of L-rhamnose transported by the phosphotransferase system of $A$. pyridinolis.

This paper describes the isolation of mutants which cannot use L-rhamnose for growth, whether or not L-malate is present. On the basis of the identification of the lesions involved and the resulting phenotypes, a pathway is proposed for L-rhamnose metabolism in $A$. pyridinolis.

\section{METHODS}

Bacteria and growth conditions. Arthrobacter pyridinolis, and mutants derived from it, were used in all experiments. PYE medium was used to maintain cultures (Sobel \& Krulwich, I973). MS was used as the defined medium (Wolfson \& Krulwich, 1972); carbon sources were autoclaved and added from separate sterile solutions to a final concentration of $0.05 \mathrm{M}$. Growth studies were conducted in $300 \mathrm{ml}$ side-arm flasks as described previously (Wolfson \& Krulwich, 1972).

Isolation of mutants. To isolate L-rhamnose-negative mutants, cells of $A$. pyridinolis were treated with ethyl methanesulphonate as described previously (Wolfson \& Krulwich, 1972). Bacteria were then washed, incubated overnight in MS plus L-rhamnose plus penicillin G $(100 \mu \mathrm{g} / \mathrm{ml})$, washed again, and plated on PYE plates. Colonies were replicaplated on to L-rhamnose and D-fructose plates. Colonies which grew on D-fructose but failed to grow on L-rhamnose were identified, picked, and characterized by testing their growth on $10 \mathrm{~mm}$ L-malate plus $50 \mathrm{mM}$ L-rhamnose, and on $10 \mathrm{~mm} \mathrm{~L}$-malate alone. Those that grew as well as the wild type on L-malate alone, and showed no increment of growth in the presence of both carbon sources were further investigated to determine the lesions involved.

Enzyme assays. Crude extracts were prepared by sonic disruption as described by Wolfson \& Krulwich (1972), and dialysed against a large volume of the buffer used in the assay. L-Rhamnose isomerase (L-rhamnose ketol-isomerase, EC. 5.3. I. I4) activity was determined by the procedure of Domagk \& Zech (1966) in which the appearance of L-rhamnulose was measured by the cysteine-carbazone reaction of Dische \& Borenfreund (I95I).

L-Rhamnulokinase (ATP: L-rhamnulose I-phosphotransferase, EC. 2.7. I.5) activity was determined in a mixture containing $25 \mathrm{~mm}-$ Tris- $\mathrm{HCl}$ buffer $(\mathrm{pH} 8.5), 2.5 \mathrm{~mm}-\mathrm{MnCl}_{2}$, $\mathrm{I} \cdot 7 \mathrm{mM}-\mathrm{ATP}, \mathrm{I} \cdot 7 \mathrm{mM}$ reduced glutathione, $25 \mathrm{~mm}-\mathrm{NaF}$, and $50 \mu \mathrm{l}$ of crude extract in a total of $0.18 \mathrm{ml}$. The reaction was initiated by the addition of $20 \mu \mathrm{l}$ of $20 \mathrm{mM} \mathrm{L}-\left[\mathrm{G}-{ }^{3} \mathrm{H}\right]$ rhamnose ( Io $\mu \mathrm{Ci} \mu \mathrm{mol}^{-1}$ ). After incubation for Io $\mathrm{min}$ at room temperature, the reaction was stopped by addition of I M L-rhamnose $(0.3 \mathrm{ml})$. Samples of the reaction mixture were spotted on DEAE-cellulose discs (Newsholme, Robinson \& Taylor, 1967). The discs were washed well in running water, dried, and their radioactivity was measured by liquid scintillation counting. A control sample was prepared by conducting the assay in the absence of ATP. The assays were linear with time and protein concentration under the conditions employed.

L-Rhamnulose I-phosphate aldolase (L-rhamnulose I-phosphate L-lactaldehyde lyase, EC. 4.1.2.19) activity was determined by following the formation of dihydroxyacetone phosphate in a reaction mixture $(0.5 \mathrm{ml}$ final volume) containing: $0.2 \mathrm{~mm}-\mathrm{NADH}$; $10 \mathrm{~mm}-$ 
$\mathrm{NaF}$; I mM- $\mathrm{MnCl}_{2} ; 25 \mu \mathrm{M}-\mathrm{MgCl}_{2} ; 20 \mu \mathrm{g} \alpha$-glycerol phosphate dehydrogenase; I $2 \mathrm{~mm}$ L-rhamnulose I-phosphate; and $25 \mathrm{~mm}-\mathrm{Tris}-\mathrm{HCl}, \mathrm{pH} 7 \cdot 6$. The reaction was started by the addition of 25 to $50 \mu \mathrm{l}$ of the supernatant after centrifuging the crude extract at $150000 \mathrm{~g}$ for 60 min in a Beckman L2-65B ultracentrifuge. The centrifugation removed most of the activity of membrane-bound NADH oxidase, which otherwise interfered with the assay. Control reactions from which L-rhamnulose I-phosphate was omitted were conducted to correct for any residual NADH oxidase activity. The decrease in extinction at $340 \mathrm{~nm}$ was followed in a $\mathrm{I} \mathrm{cm}$ cuvette in a Gilford Model 240 recording spectrophotometer at $37^{\circ} \mathrm{C}$. The amount of substrate added was probably not saturating, as L-rhamnulose I-phosphate could only be obtained in limited quantities and the affinity of the enzyme for the substrate was apparently very low. However, parallel assays of the wild type and mutants were always done and the results have been used for qualitative rather than quantitative interpretations.

D-Fructose phosphotransferase activity was assayed as described by Sobel \& Krulwich (1973). For in vitro complementation assays for phosphotransferase components, soluble and membrane fractions were prepared, as previously described (Wolfson, Sobel \& Krulwich, 1973), by centrifuging cell extracts at $150000 \mathrm{~g}$.

Protein was determined by the method of Lowry et al. (I95I) using lysozyme as a standard. Crude extracts contained 2 to $10 \mathrm{mg}$ protein $\mathrm{ml}^{-1}$. Specific activities are expressed as nmol product formed $\mathrm{min}^{-1}$ (mg protein $)^{-1}$.

Chemicals. In all experiments, the L-isomers of malate and rhamnose and the D-isomer of fructose were used. L-[G- $\left.{ }^{3} \mathrm{H}\right]$ Rhamnose was from New England Nuclear Corp. (Boston, Massachusetts, U.S.A.); NADH, ATP, and $\alpha$-glycerol phosphate dehydrogenase were from Boehringer-Mannheim Corp. (New York, U.S.A.); L-rhamnose, penicillin G, reduced glutathione and potassium thioglycollate were from Sigma; and ethyl methanesulphonate was from Eastman Organic Chemicals (Rochester, New York, U.S.A.). LRhamnulose I-phosphate was the generous gift of Dr David Feingold. All other chemicals were obtained at the highest purity commercially available.

\section{RESULTS}

Crude extracts of wild-type $A$. pyridinolis grown on L-rhamnose, prepared as described in Methods, contained L-rhamnose isomerase, L-rhamnulokinase, and L-rhamnulose Iphosphate aldolase (Table I). Isomerase and kinase activities were found only when the cells had been grown with L-rhamnose. The activity of L-rhamnulose I-phosphate aldolase, however, was the same in cells grown on L-malate alone as in cells grown in the presence of L-rhamnose.

Among the mutants which failed to grow on L-rhamnose, whether or not L-malate was present, there were three classes, typified by SL23, SL38, and SL40. Growth curves of mutants SL23 and SL38 (Fig. I) verified that they were unable to grow on L-rhamnose alone, and that when $10 \mathrm{mM} \mathrm{L-malate}$ was present, growth proceeded only until the L-malate was consumed. Extracts of mutants grown on L-malate and L-rhamnose were assayed for L-rhamnose isomerase, L-rhamnulokinase, and L-rhamnulose I-phosphate aldolase (Table I). SL38 had no detectable L-rhamnulokinase activity. SL23 had no detectable L-rhamnose isomerase activity. L-Rhamnulokinase activity could not be detected by direct assay in SL23, since we used Lrhamnose as a substrate in our assay and relied on its conversion to L-rhamnulose by the crude extract. To determine whether L-rhamnulokinase was present in the isomerasenegative mutant, a crude extract of SL23 was assayed in the presence of a crude extract of 


\section{Table I. Specific activity of enzymes of L-rhamnose metabolism in wild-type and mutant strains of A. pyridinolis}

Wild-type, SL23, and SL38 bacteria were grown in the presence of $50 \mathrm{mM}-\mathrm{L}-\mathrm{malate}$ plus $50 \mathrm{~mm}$ L-rhamnose. SL40 was grown on $50 \mathrm{mM}$ L-malate and incubated with $50 \mathrm{~mm}$ L-rhamnose for $3 \mathrm{~h}$ before harvesting. Crude extracts were assayed as described in Methods. Results are expressed as the ratio of the specific activity of the enzyme in the mutant strain to the specific activity in the wild-type strain. Specific activities of the wild-type strain of L-rhamnose isomerase, L-rhamnulo- ${ }^{1}$ kinase and L-rhamnulose I-phosphate aldolase were, respectively, I80, 27 and 6I $\mathrm{nmol} \mathrm{min}^{-}$ (mg protein) ${ }^{-1}$.

Ratio of specific activities

$\begin{array}{lccc} & \text { Rhamnose } & \begin{array}{c}\text { Rhamnulo- } \\ \text { kinase }\end{array} & \begin{array}{c}\text { Rhamnulose } \\ \text { I-phosphate } \\ \text { aldolase }\end{array} \\ \text { Strain } & \begin{array}{c}\text { isomerase } \\ \text { Wild type }\end{array} & \begin{array}{c}\text { I.00 } \\ \text { Sot tested }\end{array} & \begin{array}{l}1.00 \\ \text { SL23 }\end{array} \\ \text { SL38 } & 0.06 & 0.04 & 0.50 \\ \text { SL40 } & 1.70 & 2.80 & 0.80\end{array}$

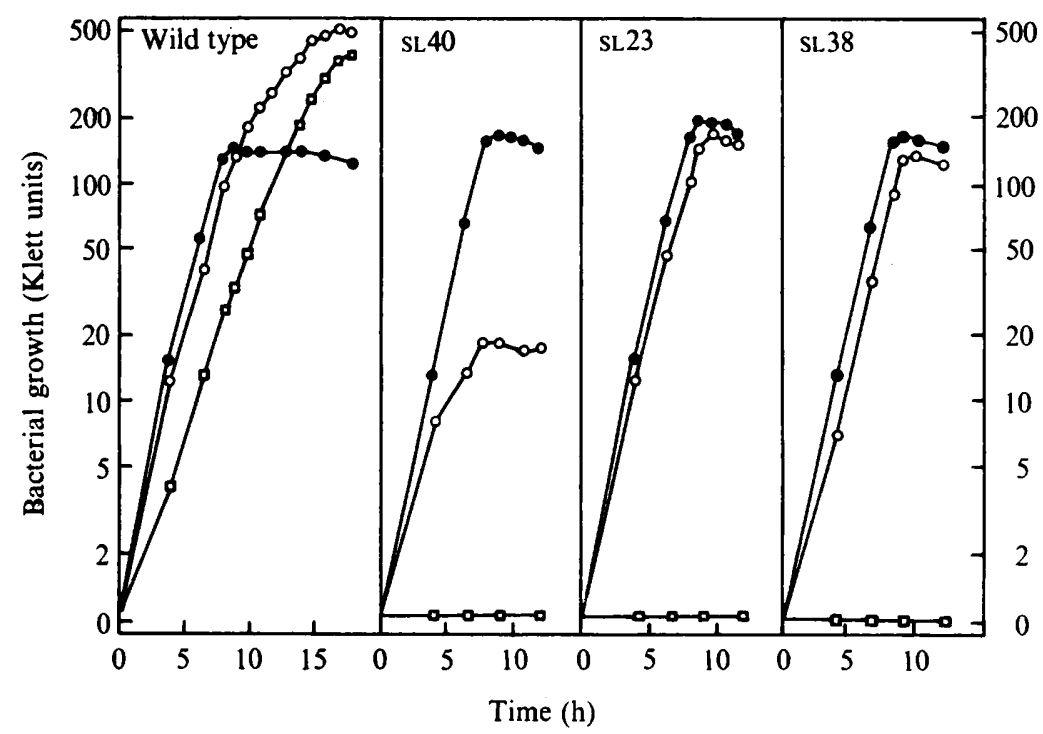

Fig. I. Growth of wild-type and mutant strains of $A$. pyridinolis on $50 \mathrm{~mm}$ L-rhamnose ( $\square$ ), IO $\mathrm{mM}$ L-malate (O), and IO $\mathrm{mM}$ L-malate plus $50 \mathrm{~mm}$ L-rhamnose $(O)$.

SL38 (which had no L-rhamnulokinase activity). The SL38 extract could convert the added L-rhamnose to the substrate for the kinase, thereby allowing the kinase activity of SL23 to be expressed. The results (Table 2) indicated that SL23 had wild-type levels of L-rhamnulokinase. In addition to showing that the isomerase and kinase were necessary for L-rhamnose metabolism, the results for these mutants showed that for purposes of supporting growth, L-rhamnose could not be metabolized via oxidation to hexonate, reduction to polyol, or incorporation of L-rhamnose I-phosphate into nucleoside diphosphate-L-rhamnose. Thus, at this point, the metabolism of L-rhamnose appeared to follow the same pathway as in $E$. coli and it was thought possible that L-rhamnose I-phosphate formed by the phosphotransferase system was simply dephosphorylated by a phosphatase acting on L-rhamnose I-phosphate. 
Table 2. Rhamnulokinase activity in mutant strain SL23 shown by complementation

Bacteria were grown overnight on $50 \mathrm{mM} \mathrm{L-malate}$ and incubated in the presence of $2.5 \mathrm{mM} \mathrm{L}$ rhamnose for $3 \mathrm{~h}$. Crude extracts were assayed as described in Methods. Specific activity is expressed as nmol L-rhamnulose I-phosphate formed $\min ^{-1}$ (mg protein $)^{-1}$.

$\begin{array}{lc}\text { Strain } & \begin{array}{c}\text { Specific } \\ \text { activity }\end{array} \\ \text { Wild type } & 4.68 \\ \text { SL23 } & 0.22 \\ \text { SL38 } & 0.58 \\ \text { SL23 + SL38 } & 4.78\end{array}$

The third class of mutant, represented by SL40, showed an unusual pattern of growth (Fig. 1). SL40 grew as well on L-malate as did the wild-type strain. It was unable to grow on L-rhamnose alone. When both L-malate and L-rhamnose were present, SL40 was unable to use either compound for growth. It appeared that the addition of L-rhamnose caused severe inhibition of growth. Similar results were obtained when $L$-rhamnose was present in SL40 cultures growing on acetate, succinate, D-fructose, L-glutamate, D-gluconate or PYE medium.

Crude extracts of SL40 contained L-rhamnose isomerase, L-rhamnulokinase, and Lrhamnulose I-phosphate aldolase (Table I). It appeared that this mutant might be defective in the hydrolysis of L-rhamnose I-phosphate, thereby allowing L-rhamnose I-phosphate to accumulate in the bacteria. In other bacteria, sugar-phosphate accumulation has been shown to cause severe inhibition of growth and, in some cases, lysis (Englesberg, I957; Kurashashi \& Wahba, 1958; Englesberg \& Baron, 1959; Yarmolinsky et al., 1959; Fukasawa \& Nikaido, 196I; Englesberg et al., 1962; Sawada \& Takagi, 1964; Chiu \& Feingold, I965; Power, 1967; Fraenkel, I968; Kelker, Hanson \& Anderson, I970; Jensen, Parkes \& Berkowitz, 1972; Solomon \& Lin, 1972; Ferenci \& Kornberg, I973; Schwartz, Abram \& Feingold, I974). Accumulation of L-rhamnose I-phosphate in SL40 might therefore account for the inhibition of growth on various substrates observed in the presence of L-rhamnose.

Since pure L-rhamnose I-phosphate was not available for use as a substrate for the postulated L-rhamnose I-phosphate phosphatase, confirmation of the defect in SL4O was obtained by indirect means. A phosphotransferase-negative derivative of SL40 was isolated which, while still unable to use L-rhamnose alone because of the original lesion, would not accumulate L-rhamnose I-phosphate in the presence of L-rhamnose. After mutagenesis of SL4O with ethyl methanesulphonate, strains were selected which were no longer able to grow on Dfructose alone, but were able to use D-fructose in the presence of L-malate, i.e. phosphotransferase-negative strains (Krulwich, Sobel \& Wolfson, 1973). Such strains, e.g. SL40I4, were still unable to use L-rhamnose alone, but had regained the ability to use this sugar in the presence of L-malate, and no longer exhibited the severe inhibition of growth seen in SL40 (Table 3).

In vitro complementation assays were conducted with mutants characterized previously (Wolfson et al., 1973), to prove that the 'L-rhamnose-insensitive' double mutants were indeed lacking a phosphotransferase component so that they could no longer produce the putative inhibitor, L-rhamnose I-phosphate. In these complementation assays, D-fructose was used as a substrate since phosphotransferase activities could be measured much more reliably with this substrate than with L-rhamnose (Levinson \& Krulwich, 1974), presumably 


\section{Table 3. Growth of strains of $A$. pyridinolis on L-rhamnose in the presence and absence of L-malate}

Bacteria were grown as described in Methods. Experiments I to 3 represent growth after $18 \mathrm{~h}$ (stationary phase) at $30^{\circ} \mathrm{C}$. Experiments 4 and 5 show net growth on L-rhamnose or D-fructose in the presence of L-malate.

\section{Carbon source}

I. $50 \mathrm{mM}$ L-rhamnose

2. $50 \mathrm{mM} \mathrm{D}$-fructose

3. $10 \mathrm{mM} \mathrm{L}$-malate

4. $50 \mathrm{mM} \mathrm{L-rhamnose}+10 \mathrm{mM} \mathrm{L}$-malate

(4 minus 3

5. $50 \mathrm{mM} \mathrm{D}$-fructose $+10 \mathrm{~mm}$ L-malate

(5 minus 3

\begin{tabular}{cccc}
\multicolumn{4}{c}{ Growth (Klett units) } \\
Wild type & SL40 & sL40I4 & SL4002 \\
385 & 0 & 0 & 0 \\
277 & 269 & 0 & 0 \\
I 22 & I 34 & I 40 & 50 \\
490 & 20 & 420 & 109 \\
368 & - I I 4 & 280 & $59)$ \\
470 & 460 & 479 & 86 \\
348 & 326 & 339 & $36)$
\end{tabular}

because with D-fructose there is no phosphatase complicating the assay. A soluble fraction from SL4OI 4 restored phosphotransferase activity to a soluble fraction from AP253, which is deficient in phosphocarrier protein, but not to a soluble fraction from AP243, which is deficient in enzyme I (Table 4). Thus SL40 4 lacked enzyme I of the phosphotransferase and therefore could not grow on D-fructose, or produce L-rhamnose I-phosphate from Lrhamnose. SL4OI3, another 'L-rhamnose-insensitive' derivative of SL40 selected for its inability to grow on D-fructose, lacked both enzyme I and phosphocarrier protein (results not shown):

The proposal that L-rhamnose I-phosphate is the inhibitory compound and that SL4O lacks L-rhamnose I-phosphate phosphatase is supported by the observation that strains unable to produce L-rhamnose I-phosphate do not show the growth inhibition observed in the parent strain SL4O. To provide further evidence that SL40, but not its phosphotransferasenegative derivative SL4OI4, accumulates L-rhamnose I-phosphate in the presence of Lrhamnose, I 1 cultures of each strain were grown on $50 \mathrm{~mm}$ L-glutamate. L-Glutamate was chosen as the carbon source because it causes relatively little repression of inducible enzyme synthesis in A. pyridinolis (unpublished results). After $24 \mathrm{~h}$, when the cells were still in the exponential phase of growth, $\mathrm{L}-\left[\mathrm{G}-{ }^{3} \mathrm{H}\right] \mathrm{rhamnose}$ was added to a final concentration of I $\mathrm{mM}\left(2 \mu \mathrm{Ci} \mathrm{ml}{ }^{-1}\right)$. The cultures were incubated for an additional $5 \mathrm{~h}$; no cell lysis (observed microscopically and by determinations of Klett units) occurred during this period. The cells were then harvested, washed twice with $50 \mathrm{mM}$-Tris $\mathrm{pH} 7 \cdot 2$, resuspended in the same buffer, and sonicated. It was anticipated that both cultures would have accumulated radioactive material, since respiration-coupled transport (and subsequent metabolism) of L-rhamnose would have occurred in the L-glutamate-L-rhamnose medium, but that only SL40 would have accumulated L-rhamnose I-phosphate. Extracts of both cultures contained 4 to $5 \mathrm{mg}$ protein $\mathrm{ml}^{-1}$. The radioactive count rate in the extract from SL40 was $\mathrm{I} 28000$ counts $\min ^{-1}$ (mg protein) ${ }^{-1}, 14 \%$ of which could not be washed off discs of DEAE (DE8I) with water. The count rate in the extract from SL40I 4 was 8 I 300 counts min $^{-1}$ (mg protein) ${ }^{-1}$, $5 \%$ of which adhered to DE8I discs under the same conditions. Samples $(0.5 \mathrm{ml})$ of each extract were then incubated for $\mathrm{I} 5 \mathrm{~h}$ at $27^{\circ} \mathrm{C}$ with $0.025 \mathrm{ml}$ of an extract prepared from wildtype $A$. pyridinolis grown on $50 \mathrm{mM}$ L-rhamnose; the wild-type extract was prepared in $50 \mathrm{~mm}$-Tris buffer $\mathrm{pH} 7 \cdot 2$, and contained $8 \mathrm{mg}$ protein $\mathrm{ml}^{-1}$. A drop of toluene was included in the incubation mixtures, and subsequent microscopic examination showed that bacterial contamination had not occurred. Samples were removed at intervals and spotted on DE8I discs, which were then washed with water and prepared for scintillation counting. 


\section{Table 4. In vitro complementation of fractions of phosphotransferase-deficient mutants with SL40I4}

Fractions of extracts of wild-type, AP243 and AP253 cells grown on $0.05 \mathrm{M}$ L-glutamate plus $0.05 \mathrm{M}$ D-fructose, or from SL40I4 grown on $0.05 \mathrm{M} \mathrm{L-glutamate} \mathrm{were} \mathrm{assayed} \mathrm{for} \mathrm{PEP:D-fructose} \mathrm{phos-}$ photransferase activity. Assays were conducted in a final volume of $\mathrm{I} \cdot 0 \mathrm{ml}$ containing $0.025 \mathrm{ml}$ of the indicated soluble fractions and $0.025 \mathrm{ml}$ of the membrane fraction from wild-type cells (a source of enzyme II). The wild-type membrane fraction and the soluble fractions from AP243, AP253 and SL4OI 4 contained I.50, $6 \cdot 8,5 \cdot 3$ and $7 \cdot 3 \mathrm{mg}$ protein $\mathrm{ml}^{-1}$, respectively. The results, expressed as $\mathrm{nmol} \mathrm{D}$-fructose $\mathrm{I}$-phosphate formed $\mathrm{min}^{-1}$ in the reaction mixture, are corrected for the amount of product formed in the presence of each of the fractions alone (generally in the range of $\mathrm{I}$ to $5 \mathrm{nmol}$ ).

Soluble fractions added
AP243 (enzyme I-deficient)+
SL40r 4
AP253 (phosphocarrier protein-
deficient) + SL40I4
AP243+ AP253

\author{
D-Fructose \\ I-phosphate formed \\ 0.95 \\ $22 \cdot 4$ \\ $38 \cdot 8$
}

The count rate of radioactive compounds from the SL40 extract which adhered to the discs decreased slowly from 17500 to 8200 counts $\mathrm{min}^{-1}$ (mg protein) ${ }^{-1}$ over the incubation period, but there was no similar decrease in the count rate of discs treated with the SL40I 4 extract. Thus, SL40, but not SL4OI4, accumulated an anionic derivative of L-rhamnose which could be degraded by wild-type $A$. pyridinolis.

Samples of $\mathrm{L}-\left[{ }^{3} \mathrm{H}\right]$ rhamnose and of the radioactive sL40 extract, both before and after treatment with wild-type extract, were spotted on Whatman no. I chromatography paper and were subjected to descending chromatography in butan-I-ol/acetic acid/water $(4: 1: 5$, by vol.; Partridge, 1948). When the solvent had moved $55 \mathrm{~cm}$, the paper was dried, and cut into I cm strips which were prepared for scintillation counting. Both experimental samples contained only one area of radioactivity which had moved from the origin. This spot was $20 \mathrm{~cm}$ from the origin and corresponded to the location of the single radioactive spot obtained from L- $\left[{ }^{3} \mathrm{H}\right]$ rhamnose. Identical volumes of SL4O extract, treated and untreated with wild-type extract, had been spotted. The radioactivity recovered at the location of the $\mathrm{L}-\left[{ }^{3} \mathrm{H}\right]$ rhamnose spot after chromatography was greater in the treated extract by an amount that corresponded to the radioactivity of the compounds which adhered to the DE8I discs. These results supported the suggestion that in the presence of L-rhamnose, SL40 accumulates L-rhamnose I-phosphate because it lacks the phosphatase which normally degrades this compound. SL4OI4 fails to accumulate L-rhamnose I-phosphate because it lacks the phosphotransferase activity which catalyses its formation.

A second group of strains was isolated after mutagenesis of SL40 by selecting for resistance to inhibition by L-rhamnose. Strains of this type, typified by SL4002, were deficient in their growth on L-malate when compared with wild-type cells (Table 3), and grew only slightly better on L-rhamnose (or D-fructose) in the presence of L-malate than on L-malate alone.

\section{DISCUSSION}

On the basis of the results obtained from mutants which cannot use L-rhamnose for growth, it is proposed that $A$. pyridinolis metabolizes L-rhamnose by isomerization to Lrhamnulose, phosphorylation to L-rhamnulose I-phosphate and cleavage to dihydroxyacetone phosphate and L-lactaldehyde. The L-rhamnose I-phosphate formed from L- 
rhamnose by the phosphotransferase system is first converted to free L-rhamnose by a phosphatase. The requirement for a phosphatase to hydrolyse the L-rhamnose I-phosphate produced by the phosphotransferase system is compatible with our consistent failure to show reproducible PEP:L-rhamnose phosphotransferase activity in bacteria grown on L-rhamnose (Levinson \& Krulwich, 1974). Also, SL40 shows severe inhibition of growth on a variety of substrates in the presence of L-rhamnose. This suggested that SL40 might be deficient in the postulated L-rhamnose I-phosphate phosphatase, so that toxic concentrations of L-rhamnose I-phosphate accumulate in the presence of L-rhamnose. This was tentatively confirmed by the observation that SL40 accumulated an anionic derivative of L-rhamnose which could be degraded to L-rhamnose by an extract of wild-type cells grown on L-rhamnose.

Two types of mutant strain which were not inhibited by L-rhamnose were isolated from SL40. SL4OI4 had lost its ability to phosphorylate L-rhamnose by the phosphotransferase system (Table 4 ). This strain was unable to grow on L-rhamnose alone. It could not form Lrhamnose I-phosphate from L-rhamnose, did not accumulate an anionic derivative of L-rhamnose which could be degraded by a wild-type extract, was no longer inhibited by Lthamnose, and was able to utilize this sugar in the presence of L-malate. The second strain, SL4002, might be deficient in the L-malate dehydrogenase necessary to couple the transport of L-rhamnose or D-fructose to respiration; this would account for its poor growth on Lmalate. The nature of the dehydrogenase is currently under investigation. SL4002 showed a small, but reproducible, increment in growth when either L-rhamnose or D-fructose was present in the medium together with L-malate; presumably the respiration-coupled transport system was operative only to the extent that the requisite dehydrogenase was also active, i.e. to the extent to which the transport system was energy-coupled. Similar, previously isolated, mutants of wild-type $A$. pyridinolis, which grew poorly on L-malate, not only showed low activity of the respiration-coupled transport system, but also failed to induce the D-fructose-specific components of the phosphotransferase system even in the presence of exogenous D-fructose. These and other results support the conclusion that active transport of $\mathrm{D}$-fructose into the cell by the respiration-coupled system is required for induction of the phosphotransferase system (Wolfson \& Krulwich, 1974). SL4002, which might be deficient in the ability to couple transport to L-malate oxidation, shows no inhibition of growth in the presence of L-rhamnose and presumably did not accumulate L-rhamnose I-phosphate. These observations suggest that this mutant could not induce the L-rhamnose-specific components of the phosphotransferase system, whose induction may require intracellular L-rhamnose, just as induction of the PEP:D-fructose phosphotransferase system required intracellular, actively-transported D-fructose. In SL4002, as well as in similar mutants, studied previously, phosphotransferase activity is not induced under conditions in which a small growth increment is observed when L-rhamnose or D-fructose is present in addition to L-malate in the medium. The small amount of sugar that these mutants are able to transport may be so rapidly metabolized that the inducer of the phosphotransferase is never accumulated sufficiently to allow induction.

Both L-rhamnose isomerase and L-rhamnulokinase are inducible enzymes. A mutant lacking detectable L-rhamnose isomerase activity contains fully induced levels of L-rhamnulokinase activity. This indicates that L-rhamnose, rather than L-rhamnulose, is probably the inducer for the L-rhamnulokinase. Moreover, mutants deficient in phosphotransferase activity synthesize the enzymes necessary for growth on L-rhamnose in the presence of Lmalate, eliminating the possibility of induction by L-rhamnose I-phosphate. It is not clear whether the isomerase and the kinase are coordinately induced with the L-rhamnose phos- 
photransferase system. It is interesting that the L-rhamnulose I-phosphate aldolase is the only enzyme in the pathway that is not inducible and is also the only enzyme in which mutations were not found. Possibly, the aldolase serves some other purpose in the cell (e.g., D-fructose I,6-diphosphate aldolase) so that under the selective conditions employed, a mutant lacking the enzyme would not be viable.

This work was supported by Research Grants GB2048I from the National Science Foundation and AMI4663 from the United States Public Health Service. T.A.K. is the recipient of a Research Career Development Award from the U.S. Public Health Service.

\section{REFERENCES}

Chiv, T. H. \& Feingold, D. S. (1964). The purification and properties of L-rhamnulokinase. Biochimica et biophysica acta 92, 489-497.

Chiv, T. H. \& FeINGold, D. S. (1965). Substrate specificity of L-rhamnulose I-phosphate aldolase. Biochemical and Biophysical Research Communications 19, $51 \mathrm{I}-516$.

ChIU, T. H. \& FeINGOLD, D. S. (1969). L-Rhamnulose I-phosphate aldolase from Escherichia coli. Crystallization and properties. Biochemistry, New York 8, 98-108.

DisCHE, Z. \& BorenFReUND, E. (I95I). A new spectrophotometric method for the detection and determination of keto sugars and trioses. Journal of Biological Chemistry 192, 583-587.

DomAGK, G. F. \& ZECH, R. (1966). L-Rhamnose isomerase. In Methods in Enzymology, vol. IX, pp. 579-582. Edited by W. A. Wood. New York: Academic.

ENGLESBERG, E. (1957). Physiological basis for rhamnose utilization by a mutant of Pasteurella pestis. Journal of Bacteriology 74, 8-I I.

ENGELSBERG, E. \& BARON, L. S. (I959). Mutation to L-rhamnose resistance and transduction to L-rhamnose utilization in Salmonella typhosa. Journal of Bacteriology 78, 675-68o.

Englesberg, E., Anderson, R. L., Weinberg, R., Lee, N., Hoffee, P., Huttenhauer, G. \& Boyer, H. (1962). L-Arabinose-sensitive, L-ribulose 5-phosphate 4-epimerase-deficient mutants of Escherichia coli. Journal of Bacteriology 84, 137-146.

Ferenci, T. \& KorNBERG, H. L. (1973). The utilization of fructose by Escherichia coli. Biochemical Journal 132, 34I-347.

Fraenkel, D. G. (1968). The accumulation of glucose 6-phosphate from glucose and its effect in an Escherichia coli mutant lacking phosphoglucose isomerase and glucose 6-phosphate dehydrogenase. Journal of Biological Chemistry 243, 6451-6457.

Fukasawa, T. \& NiKaido, H. (1961). Galactose-sensitive mutants of Salmonella. II. Bacteriolysis induced by galactose. Biochimica et biophysica acta 48, 470-483.

Jensen, P., Parkes, C. \& Berkowitz, D. (1972). Mannitol sensitivity. Journal of Bacteriology III, $35 \mathrm{I}-355$.

KelKer, N. E., Hanson, J. E. \& ANDerson, R. L. (1970). Alternate pathways of D-fructose metabolism in Aerobacter aerogenes. Journal of Biological Chemistry 245, 2060-2065.

Krulwich, T. A., Sobel, M. E. \& Wolfson, E. B. (1973). Alternate pathways of D-fructose transport and metabolism in Arthrobacter pyridinolis. Biochemical and Biophysical Research Communications 53, 258-263.

KURASHASHI, K. \& WAHBA, A. J. (1958). Interference with growth of certain Escherichia coli mutants by galactose. Biochimica et biophysica acta 30, 298-302.

LeVINSON, S. L. \& KRULWICH, T. A. (1974). Alternate pathways of L-rhamnose transport in Arthrobacter pyridinolis. Archives of Biochemistry and Biophysics 160, 445-450.

Lowry, O. H., Rosebrough, N. J., FarR, A. L. \& Randall, A. J. (I95I). Protein measurement with the Folin phenol reagent. Journal of Biological Chemistry 193, 265-275.

Newsholme, E. A., Robinson, J. \& TAYLoR, K. (1967). A radiochemical enzymatic activity assay for glycerol kinase and hexokinase. Biochimica et biophysica acta 132, 338-346.

PARTRIDGE, S. M. (1948). Filter-paper partition chromatography of sugars. Biochemical Journal 42, 238263.

PowER, J. (1967). The L-rhamnose genetic system in Escherichia coli K-I 2. Genetics 55, 557-568.

SAWADA, H. \& TAKAGI, Y. (1964). The metabolism of L-rhamnose in Escherichia coli. III. L-Rhamnulose I-phosphate aldolase. Biochimica et biophysica acta 92, 26-32.

Schwartz, N. B., Abram, D. \& Feingold, D. S. (1974). L-Rhamnulose I-phosphate aldolase of Escherichia coli. The role of metal in enzyme structure. Biochemistry, New York 13, 1716-1730.

Sobel, M. E. \& KRULWICH, T. A. (1973). Metabolism of D-fructose by Arthrobacter pyridinolis. Journal of Bacteriology II3, 907-913. 
Solomon, E. \& Lin, E. C. C. (1972). Mutations affecting the dissimilation of mannitol by Escherichia coli $\mathrm{K}-\mathrm{I}$ 2. Journal of Bacteriology III, 566-574.

TAKaGI, Y. \& SAWADA, H. (1964a). The metabolism of L-rhamnose in Escherichia coli. I. L-Rhamnose isomerase. Biochimica et biophysica acta 92, 10-17.

TAKAGI, Y. \& SAWADA, H. (1964b). The metabolism of L-rhamnose in Escherichia coli. II. L-Rhamnulose kinase. Biochimica et biophysica acta 92, 18-25.

Wolfson, E. B. \& KRULWICH, T. A. (1974). Requirement for a functional respiration-coupled D-fructose transport system for induction of phosphoenolpyruvate:D-fructose phosphotransferase activity. Proceedings of the National Academy of Sciences of the United States of America 71, 1739-1 742.

Wolfson, E. B., SoBel, M. E. \& KRULwICH, T. A. (1973). Phosphoenolpyruvate:fructose phosphotransferase activity in whole cells and membrane vesicles of Arthrobacter pyrididinolis. Biochimica et biophysica acta 32I, I $8 \mathrm{I}-\mathrm{I} 88$.

WolfSON, P. J. \& KRULWICH, T. A. (1972). Inhibition of isocitrate lyase: the basis for inhibition of growth of two Arthrobacter species by pyruvate. Journal of Bacteriology II2, 356-364.

YaRmolinsky, M. B., WiesMeYer, H. KaLCKAR, H. M. \& JoRDAN, E. (I959). Hereditary defects in galactose metabolism in Escherichia coli mutants. II. Galactose-induced sensitivity. Proceedings of the National Academy of Sciences of the United States of America 45, 1786-1791. 